\title{
Cultural memory in the museum and its dialogue with collective and individual memory
}

MERIKE LANG*

\begin{abstract}
This article analyses the forms of cultural memory (storage and functional memory) relying on the work of Aleida Assmann and the German cultural memory school (Assmann, 1999; 2004), and their changes in memory institutions ${ }^{2}$ in connection with the institution's dialogue with individual and collective memory. Assmann's theory is supplemented with museological communication schemes (Hooper-Grenhill, 1996) and a definition of the medium of collective memory (Erll, 2004). The aim of this article is to discuss the effect of functional memory in the context of the mediation work of a modern museum. The article will deal more thoroughly with the functionalizing process of cultural memory in the museum based on a specific pedagogical programme at the Estonian Open Air Museum. ${ }^{3}$

Key words: Aleida Assmann and the German school of cultural memory, museological communication schemes, the medium of collective memory, pedagogical programme, Estonian Open Air Museum.
\end{abstract}

In this articleI assert that though Aleida Assmann has observed the transformations of cultural memory primarily as they relate to institutions and linear communication with collective memory relying on museal objects (items, documents, etc), in the context of modern memory institutions it must be observed in a more abstract, synchronous dialogue with individual memory functioning on the level of meaning and understanding. Assmann has done this indirectly in her research, but the relationship between individual and collective memory that emerges in the process of functionalising cultural memory in memory institutions has not yet been specifically taken as the object of research. ${ }^{4}$ Several issues emerge in this process, for which Assmann fails to provide an answer. Hence, I consider it necessary to deal with these issues in this article using Assmann's theoretical approach as a starting point.

\section{Aleida Assmann on CUltural MEMORY AND ITS FORMS}

The definition of cultural memory according to Assmann is - the dynamic relationship between something that has been totally forgotten, changed or rejected, retained or recorded and, as a part of cultural identity, real or re- 


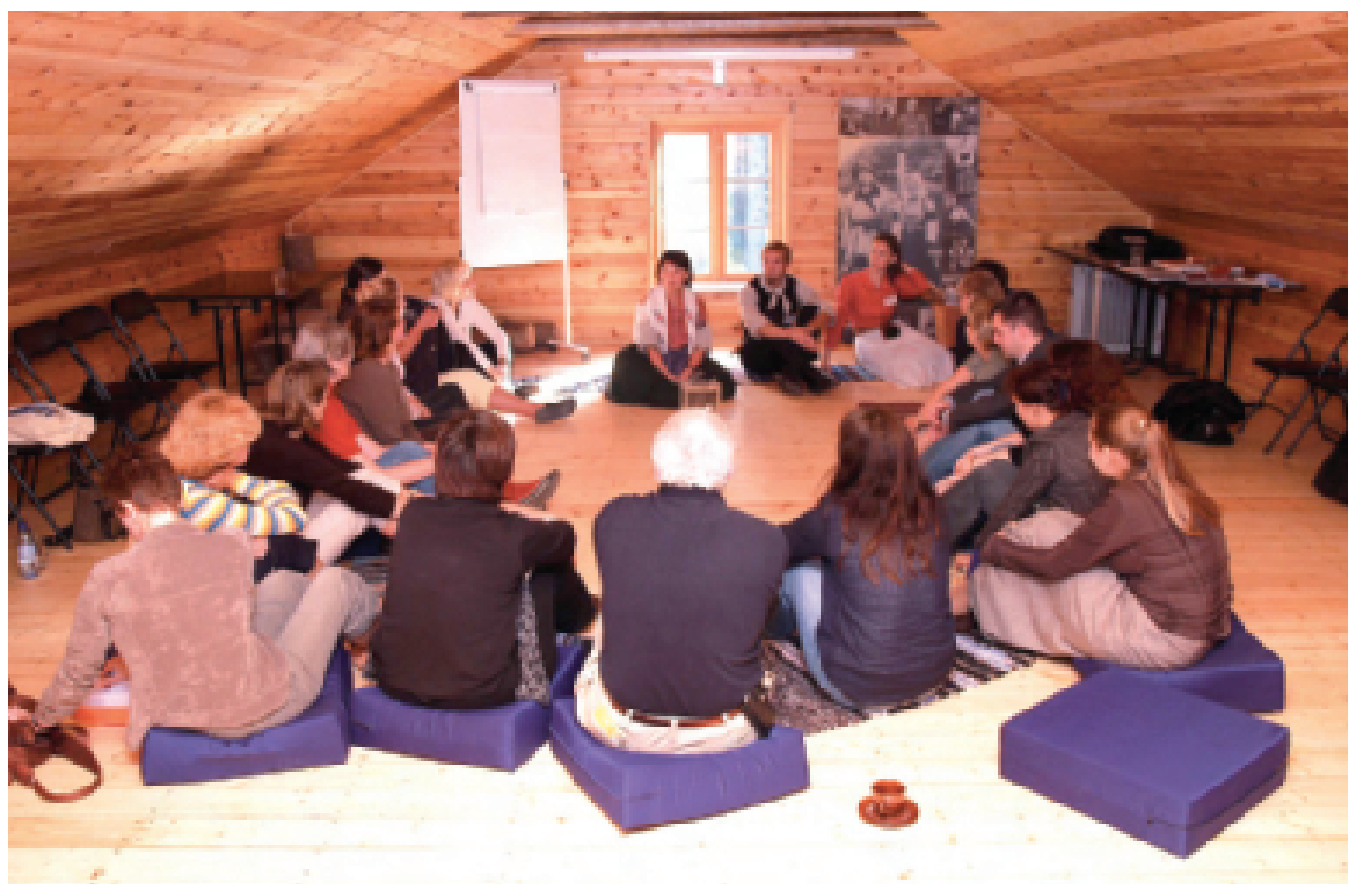

Fig. 1. Members of LLOAM (Lifelong Learning in Open Air Museums) in an educational programme discussing upon modern family values, September 2006, Estonian Open Air Museum. Photo by P. Piirmets.

membered (Assmann, 2004: 59). Cultural memory enables the communication of an individual through the ages. Cultural memory is not equal to heritage, relics or tradition, since these definitions are one-dimensional. She says that "culture" and "memory" as separate definitions are actually extensive. Though when they are put together in one definition "cultural memory" - they start to delimit each other. In delimiting the definition, cultural memory becomes a special form of memory on the one hand and a specific cultural aspect on the other hand. In the case of the latter, the definition embraces fields that differ from culture: memory as it relates to culture can be found in ways of life as well as in education, social and political organisational forms, administration and red tape, science and technology. But in all of them memory just supports those fields. According to Assmann, memory is the main impacting factor on religion, history and art. Here memory is in the foreground and culture takes the form of memory that comprises texts, activities and items (Assmann, 2004: 46-47).

With that kind of differentiation between the factors that have primary and secondary impact on culture, Assmann primarily takes cultural memory to the institutional level. Hence, the definition itself has a very large de- 
gree of generalization and can be used in the analysis of activities with institutional priorities (e.g. the executive policy of a museum). If we consider that history and art - specified by Assmann as cultural fields primarily influenced by memory - are most connected to memory institutions, ${ }^{5}$ and the institutional activity is characteristic to them, we could consider Assmann's scheme justified, but mainly with a very high degree of generalisation. Assmann herself provides the reason for a more detailed observation of the scheme. She differentiates two different forms in cultural memory - storage memory (Speichergedächtnis) and functional memory (Funktionsgedächtnis), which she has indirectly equated with the physiological property of memory - to forget and remember. Nevertheless, on observing the analysis of these forms of memory more closely, it seems that the parallel between forgetting and remembering is stronger than one would expect, and hence knowing the context of the museums more intimately, issues may arise and in presenting them I will first deal more closely with both forms of cultural memory described by Assmann.

Storage memory is connected with cataloguing, conservation and organization. Since cultural memory primarily demands institutional protection, it involves repositories such as archives, libraries and museums. (Assmann 2004: 49). They store the memory of memories, which in its essence is abstract and general - data, information, documents, memories and so on in such repositories belong to the cultural memory that no longer has a direct owner (Assmann 1999: 134137). Assmann also mentions that the archives sort the memory, and the stored items form a sort of latent memory or remnant of civilization - trash. It is not being used any more, but it acquires a new meaning in the archive - a new, marked status. The past or a person's identity can be such a mark. These kinds of remnants are structurally as important for the archive as forgetting or remembering, since the stored data carrier is treated as an aid to memory (Ibid., 21-23). So storage memory is a reservoir for the functional memory of the future and a resource for updating cultural knowledge. It enables retrieval from the context of functional memory by giving the latter an external horizon and identification cover by means of which the past is either connected, criticised or changed (Ibid., 140-141).

But Assmann certainly cannot pass up drawing parallels with physiological processes, specially with forgetting which is a similar latent memory like the past stored in a restricted Archive (Assmann 2004: 48). An individual's memory is connected to perceived memory where memories and experience are stored in different configurations forming certain set and providing self-determination for an individual (Assmann 1999: 134). On the collective level, storage memory contains nonusable, strange, neutral, abstract knowledge about identity, as well as a repertoire of missed opportunities, alternative opinions and chances not used (Ibid., 137).

Knowledge accumulated in storage memory is initially without any prospects and of no value, but through scientific meaning, reconstruction and animation and individual memory, it acquires value, meaning and organization (Assmann 2004: 48). And this, because an archives or museums are not only repositories, but also places where the past is constructed and produced. Structures are not dependant only on social, political and cultural interests, but are also determined by governing 
communication media and recording technologies (Assmann 1999: 21).

In connection with the above mentioned, the definition of functional memory emerges.

Functional memory is approached by Assmann as perceived memory characterized by group usage, selectivity, value coherence and orientation towards the future. It highlights a person's educational foundation within the construction of ideas. Cultural functional memory is connected to a subject that understands itself as its own carrier or owning itself as a subject. Collective subjects - states and nations - constitute themselves over a functional memory where they connect themselves with one certain past structure (Assmann 1999: 134-137). The design of an identity, the ability to orientate and the inherent inter-relations are central to functional memory. Here communication and identification with knowledge corresponding to the identity occurs. Functional memory is canonized through personal experience and it remains in active use for a society despite accelerating innovative changes in curricula, theatre programmes, museums, etc. Texts, objects and activities, being fixed in functional memory, always have the right to updated exhibitions, performances, texts, reading, meanings. Assmann mentions childcare and educational institutions (incl family), theatres, concert halls, exhibition halls in museums, monuments and anniversaries as institutions carrying functional cultural memory (Assmann 2004: 48-49) Generalised visions about normative history are presented in museum halls. Spatial presence and sequence refer to a passage through history for an observer. In the image rooms of history, time becomes room or a memory room structured, presented and practised for the memory (Assmann 1999: 47) At the same time, historical, biographical or religious sites and monuments are memory sites, where 65 biographical and cultural memory do not record themselves directly. Those places can only provoke memory processes via other memory media (Ibid., 21).

Assmann emphasizes that storage memory and functional memory are interconnected dialectically. In western societies, there are two different forms of the past: in functional memory it is kept extant and alive, in storage memory one may withdraw from it. The structure of cultural memory is in constant motion. (Ibid., 59-60).

These theoretical standpoints in connection with museums leave the impression that despite the links Assmann draws between both storage and functional memory and memory institutions, storage is more connected with institutions and is more independent of the governing environment than keeping cultural memory in function. Storing somehow finishes the management and an indefinite still life or forgetting or not remembering (which still is better than extinction to nowhere) follows until the moment when due to some external pressure someone remembers to find the ideas from the reservoir and put them into actions based on itemised evidence. If the existence of group recognition is a pre-requisite for functional memory according to Assmann, then does the replacement of an item, activity or text that is not useful for the group with an equivalent functionally more enhanced in their development, mean extinction, forgetting the old or its function in a changed form? I would say yes and no. The answer is obtained through the question of whether the idea or the objectified material is primary? I assert that no museum stores material in order to forget it. Behind all stored items there is the functioning idea of a museum. An item or a related definition can totally vanish 
66 from society, but the function given to it by the memory institution still operates and it is available through auxiliary materials (catalogues, registers, digital information carriers). And as strange as it might be from the standpoint of a museum as an institution, the museum employees themselves are the function carriers with their personal rather than recorded memory. The latter has an important role in designing the functional memory of the society -collecting, storing as well as mediating items and texts.

When reading Assmann, a question arises what is the critical mass of functional memory carriers? In removing a text, item or activity to the storage memory, or its commencement from there in connection with memory institutions, the question is where does this begin, by whom is it initiated and from whose standpoint is it performed? One cannot get the answers from Assmann since her approach to the changes of either form is again on a very general level, where she takes a state or nation as a carrying group and the state authorities as the initiators of changes; and hence, the processes can be explained rather diachronically. According to Assmann, the synchronisation emerges only with digitising the cultural memory and channelling it to the internet (Assmann 2004: 49-59). In my opinion, the synchronicity of the transformation of forms of cultural memory existed before digitization and other fields of activity became possible. Assmann herself again provides the key by acknowledging the perception of the museum as a memory medium and functional memory through personal experience, i.e. she refers to some communication, though leaves the topic open. I consider the verbal communication or communication on the level of understanding between a person and an institution very important from the standpoint of the construc-

\section{SENDER $\longrightarrow$ MESSAGE $\longrightarrow$ RECEIVER \\ compiler \\ curator of the exhibition \\ real things museals \\ visitor}

Fig. 1. Cameron's basic communication model (Hooper-Greenhill 1996: 22, figure 2.1).

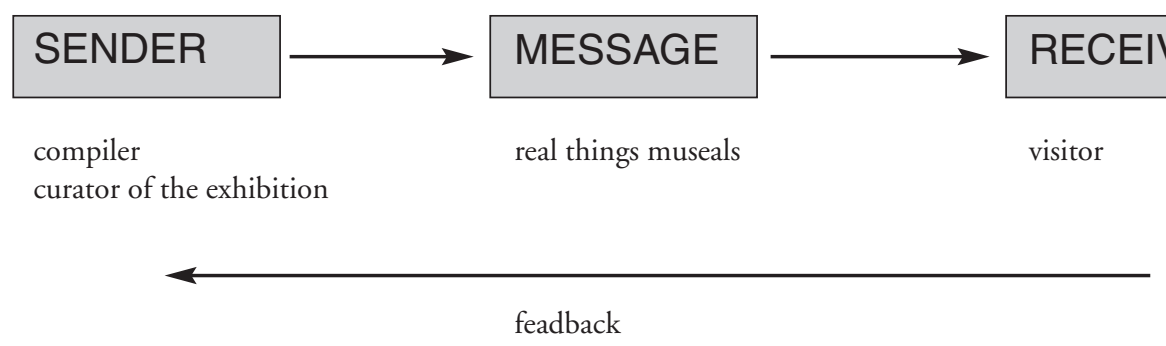

Fig. 2. Cameron's model with feedback (Hooper-Greenhill 1996: 23, figure 2.3). 


\section{TEAM OF TRANSMITTERS}
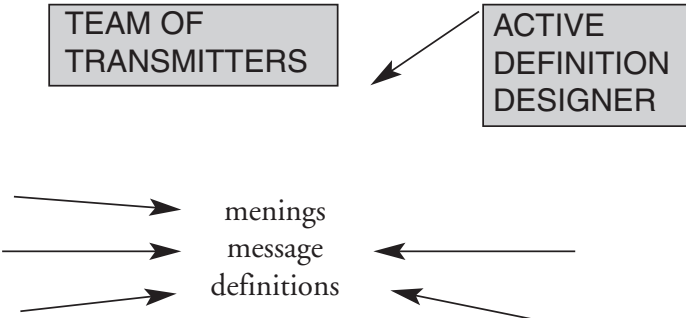

menings

message

definitions

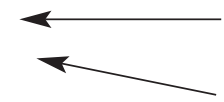

Fig. 3. Mounin's new museum communication model (Hooper-Greenhill 1996: 25, figure 2.4)

tion and effect of cultural functional memory. I assert that fixing a text or an item in functional memory and preserving it there is connected to a reciprocal dialogue of sender and receiver, and it does not always assume support from a material object. The latter might only support the emotions of partners in a dialogue. Before explaining this statement based on a specific example, the communication models of museum must be dealt with.

\section{MUSEUM COMMUNICATION MODELS}

Three communication models (figures 1-3) can be followed in the communication with society/visitor from the 19 th century.

The basic communication model (fig 1, Hooper-Greenhill 1996: 22) prevailed until the middle of the 20th century when museums could be quite sovereign in structuring functional memory. A text or an item as a recognizable mark whether it did or did not reach the awareness/use of the receiver. Structuring functional memory was grounded with scientific requirements (items that were nice, unique, artistic or valued in some other way, and systematic exhibits based on scientific ideas were presented). The subsequent basic com- munication model with feedback (fig 2, Hooper- Greenhill 1996: 23) started to consider the opinions of visitors about the success and intelligibility of an exhibition and recommendations were considered in preparing the following exhibitions. In connection with that, the amount of supporting texts that could facilitate the receiver in assimilating the text increased. In general, the model is still in use, but it is more used for marketing opinion polls to plan the use of better functioning information channels in the future.

From the point of view of structuring the functional memory, the principles of preparing the exhibitions and educational programs are of more interest for us. Here the museum employee considers the level and ability of the receiver to understand, and this process is described by the modern museum communication model (fig 3, Hooper-Greenhill 1996: $25)$. It deals with the museum and its expositions as a system of meanings, where the message forwarded by the museum acquires its real meaning only after the participation of the receiver in the interpretation. In this case, the receiver is an active partner in the dialogue, who designs the meaning according to his or her previous experience, knowledge, attitudes, values - i.e. for everything he or she possesses socially participating in each interpretation. So the message becomes a central mediating part between the sender and the receiver-interpreter, where different meanings are completed and reformed. This central part is always in motion. Each new interpreter brings new interpretations for a mediation determined by us (Hooper-Greenhill 1996: 25). At the same time, this model refers to withdrawal from object centeredness and leads to a more abstract level of the definition of communication. 
In practice, a state-of-the-art model means that the curator and pedagogue of the exhibition must consider the individual memory of the receiver in interpreting history as well as the present. Since individual memory, according to Assmann, discloses the line between choices, configurations of elements joined using a narrative where only a certain portion of the memories is selectively brought up to date (Assmann 1999: 135); in considering this the museum has to make choices: to decide what to explain in more detail about the information stored in the cultural memory and where to trust the competence of the receiver or the dialogue. The volume of this article does not allow us to handle all possible forms of dialogue between the visitor and the permanent exposition or exhibition, ${ }^{6}$ hence the author focuses on the more clearly observable dialogue that functions in structuring the functional memory in a pedagogical programme, where the active participation and role of a visitor helps. At the same time I put an equal sign between an exhibition and an educational programme though the former with its object centeredness is closer to Assmann's approach to cultural memory.

\section{THE PEDAGOGICAL PROGRAMME IN A MU- SEUM AS A MEDIUM OF COLLECTIVE MEMORY}

Aleida Assmann states that what the written and visual media cannot mediate is now mediated using new museum pedagogy that handles history as experience. The intended elaboration and added colour should deepen the individual's acquisition of historical knowledge. Assmann does not however, delve into the intended process of historical elaboration and refers to items and memory sites (e.g. monuments, battlefields, concentration camps etc.) in museum collections as memory media or mediators between the past and the present (Assmann 1999: 330-331). Her approach is again objectified and linear. A programme related to the informal pedagogical activity of the museum often does not need the items or sites. I assert that it is itself a medium using the scenario of personal and collective memory as an auxiliary means, when the experience, as part of the dialogue, becomes new cultural knowledge to be remembered, retold or which may be taken as the model for certain information and where museal items assume a secondary role.

Proceeding from the latter, I use the definition of a collective memory medium in my approach (Medium des kollektiven Gedächtnisses. Erll 2004). I understand the independent educational programmes and exhibitions provided in museums as historically and culturally specific phenomena, and observe them as collective memory media. Siegfrid J. Schmidt's definition describes it as a complex definition of cultural scientific memory-research where the medium can be mediated or remembered (Schmidt 2000: 93 jj, cit. Erll 2004: 12-13). A memory medium is constructed on several levels from different factors and their so-called cooperation takes place in specific cultural memory contexts. The medium is produced, carried and received according to certain experiences, expectations, orders of knowledge, memory practice and memory competitors (Erll 2004: 18). A memory medium consists of four components (Erll 2004: 14-17). I name them here with my own examples to which I add support in further discussions:

1) communication instruments capable of semiosis that establish the pre-requisites for selecting information worth remembering 
and forming collective memory: people participating in a museum's educational programme, language, historical items (or museals);

2) media technologies that expand the contents of the memory and allow it to be disseminated: discussion, role plays, photographic recordings, sculptural form;

3) social systematic institutionalisation necessary for the canonization, production and representation of the medium: a team cooperating within the framework of the museum's educational programme that decides which media are active within the structure;

4) a memory message ${ }^{7}$ via an educational programme as an output involving new knowledge as a reconstructed historical narrative - a story re-told and remembered. As with functional memory, one of its tasks is the legalisation of the memory or making it stand out and serve the collective identity. ${ }^{8}$ Now I will observe the joint effect of these components using the example of an educational programme at the Estonian Open Air Museum. The aim of the programme was to become acquainted with the model of a traditional farm household and relations between the households necessary for understanding the everyday life of that family among the farmhouses now in the permanent exposition. But at the same time, a pre-requisite of the programme was not staying in an authentic environment. It was necessary to design the historic family model using our own knowledge and skills in order to obtain an experience based on new knowledge and to be able to understand it in light of our modern life style.

The programme has been enacted by means of a role-play involving adults and children visiting the museum. Since the analysis of the present on the basis of the participants and the construction of the past through group cultural and collective memories and personal semantic or episodic memories are interconnected in the activity, I handle the adult training. Here the "glossary" of the participants' knowledge and memory is larger. The group experience and knowledge is highlighted with discussions, stories and role-plays using first ${ }^{9}$ as well as third person ${ }^{10}$ interpretations. Though the first person interpretation of history has been criticized by academic historians and museum employees that like the truth, this particular didactic tool can be justified through the context of the memory institution and collective memory medium. I see one memory medium component in it - media technology. New knowledge and experience by means of teaching the subject, learning and systematic checking of knowledge, are not designed in the informal museum lesson as in a formal school education. Here the emotional involvement of a visitor is used with the help of items and activities supporting personal memory or stimulating remembering. This is exactly how the memory processes necessary for the interpretation and construction of new experiences are induced and the understanding of the message is taken to the personal level of the receiver. The activity is very close to group therapy and psychodrama sessions. The museum integrates from there certain elements considering their own aims. ${ }^{11}$ It must be mentioned here that it is not a historical reality that is constructed in the museum, but the forms of knowledge about reality (Deneke, 1985: 15) - single topics or memory messages possible for the museum and necessary for the interest of processes in the society or discussions performed there to be handled relying on existing material. 
70 The target group of the described programme as well as the communication instrument capable of semiosis were the educational field professionals from the open-air museums of Finland, Sweden, Denmark, Russia, Lithuania, Germany, Belgium, Great Britain and Estonia. One may ask whether people can be instruments in memory media? I assert that they can since the media forms only due to the activity of the participants. A higher than average knowledge about the methodical possibilities of an informal museum education and in the field of the mental and material culture of homeland united the people participating in the programme. But the above-mentioned international group did not have an integral group memory in presenting this 19th century Estonian story. The only thing that united them was an assumed knowledge about the broadest common signs (values, attitudes, work distribution, etc) of European peasant society.

Though an open-air museum with its environment is one of the strongest supporters of a role-play, the existence of an authentic environment is not a pre-requisite for performing a role-play; it is only supportive. At the same time it is not logical that a museum does not use any material item from history as an instrument favouring understanding and interpretation. For example, the attitude towards the role-play among the participants in a specific group and their readiness to use it in the process of acquiring real knowledge varied considerably. In analysis of the programme one person revealed that if there had not been the request to find some kind of attire to mark one's role and if it were not so horrible looking for him/her (it was just a single felt hat) s/he would not have been able to delve into the role. He also revealed that this was his first role-play in a museum programme.
In the memory medium described here, the people, the language they used with each other and material distributed to them were the instruments of the medium. Those instruments helped to create and specify the semiosphere within the borders of which the medium started to function. The need for maximum sign limits was due to the large scale of the topic and the time frame of the programme. For a historic exhibition or museum programme to have the potential to become a memory medium, and to change in a manner that is personally acceptable for the receiver and that the memory will become functional, success can only depend on the museum involving the visitors. The motivation to participate and get engaged in the process needs to be created. In this example, the aim was to try to make the family relations of quite a strange era understandable for contemporary people. Individual and collective memory, knowledge, momentary preferences, emotions and so on became decisive. A reconstruction of history was performed by means of remembering and using personal knowledge, where the semiosis was limited to modern family values and describing a specific individual's family. Hence the programme achieved interest, the courage to express something and personal contact between the participants. Single teams were formed to construct a common topic on the basis of the 1-2 most frequently mentioned key words (e.g. love and care) in the discussion touching rather personal feelings, and based on a consensus that characterizes a modern family. I call these social systematic institutions of a memory medium whose role is to take care of constructing the medium, provide solutions, etc. In this lesson they first had to fix a modern narrative as a memory messa- 


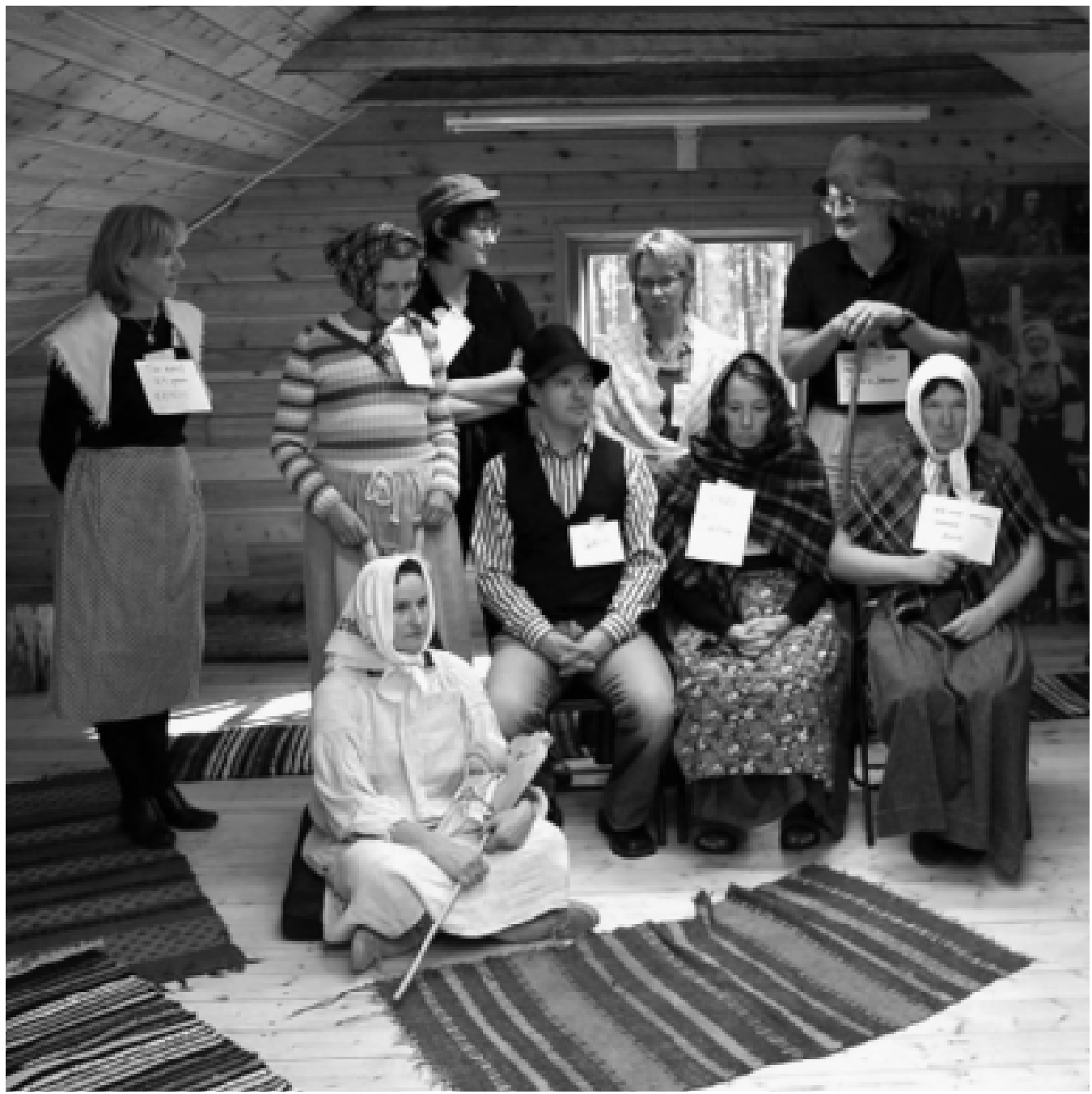

Fig. 2. Vision of a 19th-century Estonian peasant family, its composition and hierarchy, as presented by one of the working groups. Members of the working group accentuate their roles with vivid articles of clothing and wear a label describing their character. Photo by P. Piirmets.

ge with a sign of a "living sculpture" and then to go back to the assumed past. The sculpture became a memory medium instrument towards subsequent activity that fixed the achieved experience and gave a figurative characterisation to a common decision, which had to separate the quality of the present from the constructed figure in the past. 
72 For example, a sculpture marking love and caring was a round set of people holding hands that from time to time opened itself with a friendly wave of the hand outside the circle.

The reconstruction of history started with selecting the roles. Here the participants had to know or presume who could belong to the 19th century family and decide which roles they wanted to take. Without doubt they also had to remember their own history knowledge or draw parallels with family traditions. The recommendations of the group leaders operated here as a guide to activate the remembrance. The selection of the roles had to be justified. It would take a long time to transcribe the discussions of the leaders and group members based on history or family stories. To conclude, it can be said that the roles were mainly taken according to some momentary personal interest, bright personal episode or semantic memory, knowledge stereotype or future dream; for example, the desire to become a mother or personify a great grand parent with an astounding character, to feel oneself as an important owner or powerful grey cardinal, cute youngest child, or proud eldest child and so on. The choice of one group member was quite curious. S/he wanted to be the youngest of the family, but unfortunately born deaf and dumb. Since s/he was a colleague participating in the event and had to use the help of an interpreter, s/he could have remained a wordless participant. Unexpectedly s/he became the brightest designer of the whole 19th century family model. A child born from love, but disabled was, according to the old lady of the house, a curse for letting a daughter in law with little money into the family. They were ready to take care of the child, but from the point of view of property and the continuity of the farm, the child did not have any future. Even an education, allowed for the youngest child at that time, was not available. With common knowledge and the guidance of a supervisor, the story or memory message from a loving 19th century family was formed. But since at that time there was the opinion that love cannot be the basis for guaranteeing the continuing material security of the farm, the group participating in the lesson formulated their own harsh punishment - a disabled child. To conclude, the historic family and its relations were fixed in a family picture where the characteristics of hierarchy and seriousness of the era dominated.

The message of the lesson was especially clear when considering the differences between the human sculpture depicting a modern family and the final picture of the historic family. As a digression, I would like to draw our attention to the colleague who played the deaf and dumb child - during the several seminar days s/he had no problems communicating with the others through an interpreter, but during the analysis s/he became scared on experiencing how little future one might have if one was not able to communicate or if one had not suggested the capability him/herself (in this case $s /$ he referred to the ability to speak a foreign language). The general opinion among all the participants was that they got to know something about a model family on a farm in 19th century Estonia. It was interesting and unexpected in comparison to their own cultural space today as well as in the past. It was also surprising how, with little means, it is possible to guide a person through a role play to open their personality, life and dreams, and put their outwardly useless identities to the service of constructing a cultural memory as part of a museum's aims. 


\section{CONCLUSION}

Joining culture and memory into an integral definition of cultural memory has provided interesting results for research into culture. It has made it possible to provide a theoretical framework for phenomena and their objectified material from their past, which states and nations have considered valuable and worthy of preservation for subsequent generations. Aleida Assmann and the German cultural memory school observes cultural memory through the definitions of storage memory and functional memory, and approaches the transformations of forms of memory at the state and national level through a very generalised view. When identifying some memory venues (exhibition halls and so on), memory sites (monuments, battle fields an other) and memory supports (items, activities, texts), a rather object centred approach is taken on the institutional level. This in turn supports a diachronic, linear communication (basic communication model) with collective as well as personal memory where the latter becomes secondary. Nevertheless, if we consider the conditions under which the reanimation of a memory takes place in memory institutions, an active synchronous dialogue between the sender and the receiver (communication model acting on the system of meanings) in constructing the functional memory should be recognized. Thanks to a very high dependence on the aims of the sender and personal memory, and the experience and needs of the receiver, the cultural functional memory that emerges through the activity of the museum takes the face of the institution that helped to construct it as well as the target group interested in receiving the message. This should not satisfy the generalized canons of official school programmes, but supplement them by adjusting the colour of the programme to suit the identity of a certain recipient group. It should remain a largely person-centred memory support circling the cultural functional memory as a component characterizing a certain interest group.

By identifying the object-based exhibition in this article as a medium with an independent informal educational programme carried out in a museum and by doing so analyzing the latter with the help of the definition of the medium of collective memory, the role of the recipient, his/her memory and life within the cultural memory becomes clearer. The didactic method of the educational programme described here was one of the most extreme in terms of the activity, but here the processes functioning in practice, which should also be considered in theoretical structures, were more clearly highlighted. The activities of contemporary museums are very strongly connected not only with the support, design or retention of the identity of general but also unique target groups. Single observations of components in a collective memory medium in the context of a specific group show the strengths or weaknesses of the components and the potential for making them stronger or weaker. Since in the collective memory medium, the importance of a person as a factor throughout all components, the museum as the mediator of cultural memory cannot foresee the real contents of the experience received from the programme. The same is also true for the exhibition, which is also one of the forms of the functional memory being its objectified expression. Differences in the behaviour of the visitors refer to the differences in understanding and the synchronous dialogue with the presented material. 
74 Aleida Assmann's cultural memory approach on the institutional, state and national level creates a limiting framework for the analysis, but in asking specific questions it becomes evident that at present there is no cultural memory unambiguously understandable or functionalized by the government or school curriculum. The contemporary memory institutions with their informal educational activities are the ones who make their corrections to this understanding. It is easier to understand it by using the complex definition of the collective memory medium and the function of its components in analyses. Only the mutual cooperation between the latter can create the basis for functionalizing the memory. Here we also find that when talking about cultural memory, initially, we have to limit the semiosis precisely in terms of where it functions or in terms of the frameworks and conditions within which it changes. Verbal as well as presentable cultural forms should have a larger role beside the objectified forms located at the institutional level.

\section{Notes}

1. The article is compiled within the framework of ETF grant 6687 "Memory places and remembrance cultures in XXI century Estonia".

2. Memory institutions mean archives, libraries and museums.

3. Estonian Open Air Museum in Tallinn, the capital of the Republic of Estonia is a central state museum researching, collecting, retaining and mediating Estonian country architecture and everyday life matters related to it (http://www.evm.ee 1.04.2007.).

4. Also, biography researchers have emphasized the need to consider a larger role of individual me- mory in fixing collective memory (Kōresaar 2003: 10-14).

5. A. Assmann says that memory institutions have given cultural memory its strength from the spread of historicism in the XVIII and XIX century (Assmann, 2004: 50-51).

6. See the Master thesis "Museological communication. Place and tasks of Open Air Museum in modern society" by M. Lang written for defending the master's degree of social sciences in Tallinn University in 2005.

http://www.muuseum.ee/uploads/files/merike_la ngi_magistrit.doc (7.03.2007).

7. Astrid Erll understands cultural objects and their formal patterns as specific memory media as memory messages (Erll 2004: 15) but as mentioned above I handle the museum's pedagogical programme as independent and equal to an exhibition hence also as a memory message.

8. With the last statement I will still draw parallel with Assmann's cultural memory school (Assmann 1999: 138-139) with which I refer to the necessity to extend the approach.

9. First-Person Interpretation - the act of portraying a person from the past (real or composite). The standard form is one in which the interpreters refer to the past in the present tense; employ a combination of techniques including storytelling, demonstration, question and answer, and discussion; encourage verbal interaction from the audience; and avoid breaking character (www.voicenet.com/ frstprsn/alhfam/glossary.ht m 1.04.2007).

10. Third-Person interpretation - informative, often interactive talks and demonstrations by interpreters who may be dressed in period attire but do not assume character roles (www.voicenet.com/ - frstprsn/alhfam/glossary.ht m 1.04.2007).

11. Public narration of personal life and experience, their discussion (according to explanations of ex 
manager Triin Siiner of Estonian Open Air museum educational centre).

\section{LITERATURE:}

ALHFAM (The Association for Living Historical Farms and Agricultural Museums - Gossary: First-Person Interpretation, compiled by Stacy F. Roth. [online] <http://www.voicenet.com/ - frstprsn/alhfam/glossary.htm (1.04.2007)

Assmann, Aleida: Erinnerungsräume. Formen und Wandlungen des kulturellen Gedächtnisses. München: Verlag C. H. Beck, 1999.

Assmann, Aleida: Zur Mediengeschichte des kulturellen Gedächtnisses. - In: Media and Cultural Memory / Medien und kulturelle Erinnerung. Edited by / herausgegeben von astrid Erll, Ansgar Nünning. 1. Medien des kollektiven gedächtnisses. Konstruktivität - Historizität - Kulturspezifität. Berlin, New York: Walter de Gruyter, 2004, p. 45-60.

Deneke, Bernward: Realität und Konstruktion des Geschichtlichen. - In: Kulturgeschichte und Sozialgeschichte im Freilichtmuseum. Historische Realität und Konstruktion des Geschichtlichen in historischen Museen. Referate der 6. Arbeitstagung der Arbeitsgruppe "Kulturgeschichtliche Museen" im Museumsdorf Cloppenburg - Niedersächsisches Freilichtmuseum, herausgegeben von Helmut Ottenjann. Cloppenburg, 1985, p. 9-20.

Echterhoff, Gerald: Das Aussen des Erinners: Was vermittelt individuelles und kollektives Gedächtnis? - In: Media and Cultural Memory / Medien und kulturelle Erinnerung. Edited by / herausgegeben von astrid Erll, Ansgar Nünning. 1. Medien des kollektiven gedächtnisses. Konstruktivität - Historizität - Kulturspezifität. Berlin, New York: Walter de Gruyter, 2004, p. 61-82.

Erll, Astrid: Medium des kollektiven Gedächtnisses ein (erinnerungs-) kulturwissenschaftlicheer
Kompaktbegriff. - In: Media and Cultural Memory / Medien und kulturelle Erinnerung. Edited by / herausgegeben von astrid Erll, Ansgar Nünning. 1. Medien des kollektiven gedächtnisses. Konstruktivität - Historizität - Kulturspezifität. Berlin, New York: Walter de Gruyter, 2004, p. 322.

Hooper-Greenhill, Eilean (Editor): The Educational Role of the Museum. London, New York, 1996.

Kõresaar, Ene: Mälu, aeg, kogemus ja eluloouurija pilk. - Rmt: Mälu kui kultuuritegur: etnoloogilisi perspektiive. Kõresaar, Ene, Anepaio, Terje. Tartu Ülikool, 2003, p. 7-32.

Lang, Merike: Museoloogiline kommunikatsioon. Vabaôhumuuseumi koht ja ülesanded kaasaegses ühiskonnas. Magistritöö Tallinna Ülikooli sotsiaalteaduse magistri kraadi taotlemiseks. Tln., 2005. [online] http://www.muuseum.ee/uploads/files/merike_langi_magistrit.doc (7.03.2007).

Schmidt, Sigfried J.: Kalte Faszination: Medien, Kultur, Wissenschaft in der Mediengesellschaft. Weilerswist: Velbrück 2000.

${ }^{*}$ Merike Lang is since 1992 a director of the Estonian Open Air Museum. She holds a master degree in social sciences in museological communication. She is a PhD Student at University of Tartu, Fakulty of Philosophy (ethnology). She works in the framework of the Estonian Science Foundation's grant No 6687, "Sites of Memory and Cultures of Remembrance in the 21st Century Estonia”.

Address: The Estonian Open Air Museum, Vabaōhumuuseumi tee 12, Tallinn 13521, Estonia

Phone 00372-6549100, Fax 00372-6549127 merike@evm.ee 